\title{
Progression of snoring and obstructive sleep apnoea: the role of increasing weight and time
}

\author{
G. Berger*, R. Berger* and A. Oksenberg ${ }^{\#}$
}

ABSTRACT: The aim of the present study was to examine the natural evolution of primary snoring and obstructive sleep apnoea (OSA) in adult male patients.

Retrospective analysis was performed on 160 untreated patients with primary snoring and mild, moderate and severe OSA who had two polysomnographic recordings. The mean time between recordings (TBR) was $5.1 \pm 3$ yrs.

The mean apnoea/hypopnoea index ( $\mathrm{AHI})$, body mass index (BMI), and lowest arterial oxygen saturation level during rapid eye movement (REM) and non-REM sleep showed a significant worsening effect. The change in AHI differed among the groups showing a similar significant increase in AHI for primary snoring, mild and moderate OSA and an insignificant decrease for severe OSA patients. Stepwise linear regression showed that only $\triangle B M I$ and time were significant predictors for $\mathrm{AHI}$ change. A model for the mean $\mathrm{AHI}$ change showed that $\Delta \mathrm{AHI}=(4.33 \times \Delta \mathrm{BMI})+$ $(0.66 \times$ TBR $)$. After adjusting for confounders, multiple regression analysis indicated that age and high BMI, but not $\mathrm{AHI}$, were significant risk factors for developing hypertension and/or cardiovascular disease.

Patients with primary snoring and mild and moderate obstructive sleep apnoea had a similar increase in the apnoea/hypopnoea index over time, which depended mainly on weight gain and, to a lesser extent, on time.

KEYWORDS: Apnoea/hypopnoea index, body mass index, natural evolution of disease, obstructive sleep apnoea, polysomnography, snoring

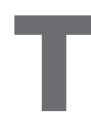
he study by LUGARESI et al. [1] was the first to theorise that prolonged snoring for years, and even decades, antedated the appearance of overt obstructive sleep apnoea (OSA). However, owing to the sparse and conflicting data available to date, controversy arises as to whether OSA is a progressive disease. In total, 18 longitudinal studies have dealt with the evolution and risk factors associated with snoring and OSA syndrome [2-19]. Several studies found that mild-to-moderate OSA has a tendency to worsen over time [2-11]. Other clinical trials found that apnoea status is fairly stable over time [12, 14-19] or even improves [13]. Of these 18 studies, nine include subjects from the general population and four of them comprise a large number of participants (between 282 and 2,968 subjects) and are relatively new studies. The other five are much older studies, include fewer participants and mostly comprise an elderly population. Of these 18 studies, nine assessed patients seeking treatment, but most of them are relatively old studies including a small number of participants (between 11 and 55), which did not allow meaningful subgroup comparisons. All but one study included both sexes [6]. In some studies the time between the two polysomnographic (PSG) evaluations was relatively short $[4,5]$ or analysis was restricted to an older population (table 1) [3, 12, 14, 16, 18].

The answer to the question of how to approach interest. A progressive nature of disease would dictate early and frequent follow-up visits for patients with primary snoring and mild OSA and treatment planning at an early stage [20]; however, the opposite would hold true for a stable disease.

The present authors followed up 160 untreated adult males over a mean period of $5 \mathrm{yrs}$, aiming to study the natural evolution of snoring and OSA in primary snorers and in patients with mild, moderate and severe OSA. The risk factors that may play a role in the progression of these conditions was investigated. snoring and OSA has more than academic

\section{AFFILIATIONS}

*Dept of Otolaryngology-Head and Neck Surgery, Meir Medical Center, Kfar Saba, and

\#Sleep Disorders Unit, Loewenstein Hospital Rehabilitation Center,

Raanana, Israel.

CORRESPONDENCE

A. Oksenberg

Sleep Disorders Unit

Loewenstein Hospital Rehabilitation Center

Raanana 43100

Israel

Fax: 97297703123

E-mail: arieo@clali.org.il

Received:

January 282008

Accepted after revision:

October 142008

STATEMENT OF INTEREST

None declared.

European Respiratory Journal

Print ISSN 0903-1936

Online ISSN 1399-3003 
TABLE 1 Primary snoring and obstructive sleep apnoea: progressive or stable

\begin{tabular}{|c|c|c|c|c|c|c|}
\hline First author [ref] & Subjects $n$ & Sex & Mean age yrs & Group type & PSG settings & Follow-up \\
\hline \multicolumn{7}{|l|}{ Progressive } \\
\hline BLIwISE [2] & 15 & $\mathrm{M} / \mathrm{F}$ & 73.6 & GP & Sleep lab & $2.8 \mathrm{yrs}$ \\
\hline РНOHA [3] & 11 & $\mathrm{M} / \mathrm{F}$ & 66 & ST & Sleep lab & $3 \mathrm{yrs}$ \\
\hline SVANBORG [4] & 42 & $\mathrm{M} / \mathrm{F}$ & 55 & ST & SCSB/PSG & 15.6 months \\
\hline Peppard [7] & 690 & $\mathrm{M} / \mathrm{F}$ & 46 & GP & In-home & $4 \mathrm{yrs}$ \\
\hline Young [8] & 282 & $\mathrm{M} / \mathrm{F}$ & $30-60^{\#}$ & GP & In-home & $8 \mathrm{yrs}$ \\
\hline REDLINE [9] & 486 & $\mathrm{M} / \mathrm{F}$ & 32 & GP & In-home & $5.3 \mathrm{yrs}$ \\
\hline NeWman [10] & 2968 & $\mathrm{M} / \mathrm{F}$ & 62 & GP & In-home & $5 \mathrm{yrs}$ \\
\hline SAHLMAN [11] & 28 & $\mathrm{M} / \mathrm{F}$ & 50.2 & ST & In-home & $3.9 \mathrm{yrs}$ \\
\hline \multicolumn{7}{|l|}{ Stable } \\
\hline SFORZA [15] & 32 & $\mathrm{M} / \mathrm{F}$ & 51 & ST & Sleep lab & $5.7 \mathrm{yrs}$ \\
\hline $\mathrm{HoCH}[16]$ & 50 & $\mathrm{M} / \mathrm{F}$ & $61-87^{\#}$ & GP & Sleep lab & $3 \mathrm{yrs}$ \\
\hline QUAN [17] & 17 & $\mathrm{M} / \mathrm{F}$ & 53 & ST & Sleep lab & $6.9 \mathrm{yrs}$ \\
\hline ANCOLI-ISRAEL [18] & 58 & $\mathrm{M} / \mathrm{F}$ & 73 & GP & In-home & $18 \mathrm{yrs}$ \\
\hline FISHER [19] & 40 & $\mathrm{M} / \mathrm{F}$ & 47 & ST & Sleep lab & $5 \mathrm{yrs}$ \\
\hline
\end{tabular}

Note that all studies used two polysomnographic recordings to compare progression of apnoea/hypopnoea index. PSG: polysomnography; M: male; F: female; GP general population; ST: seek treatment; SCSB: static charge sensitive bed. ${ }^{\#}$ : age range.

\section{MATERIALS AND METHODS Patient selection}

A retrospective, longitudinal case study of untreated adult males who had primary snoring and various degrees of OSA were followed at the Sleep Disorders Unit (Loewenstein Hospital Rehabilitation Center, Raanana, Israel), between 1989 and 2004. Only patients who had two overnight PSG for $\geqslant 4 \mathrm{~h}$ sleep each on separate occasions, $\geqslant 6$ months apart were included. Patients using either continuous positive airway pressure (CPAP), bilevel positive airway pressure, an oral appliance or tennis ball technique and those who had nasal, oropharyngeal or bariatric surgery between recordings were excluded from the analysis. In addition, patients who had split-night examinations and patients with predominant central apnoeas, neuromuscular disorders or who were mentally retarded were excluded. After the exclusion criteria were applied, 160 patients were left and comprised the research group.

Each patient completed a questionnaire for demographics, sleep habits and symptoms, and general medical condition data. Further data on years of snoring, smoking habits and concomitant diseases including hypertension (HT) and cardiovascular disease (CVD) were collected. Following initial PSG recordings, all patients were advised, when appropriate, to reduce weight and/or use CPAP, an oral device, or tennis ball technique, but either refused or had poor compliance. The request for a second PSG came from the referral physician who decided to ask for a re-evaluation based on the patient's symptoms. The patients were not paid to undergo the second examination. The patients belong to the Clalit Health Care Services (Tel Aviv, Israel) which is the largest Health
Maintenance Organization in Israel, providing medical services to $\sim 60 \%$ of the total Israeli population. Polysomnography is included in the medical services free of charge.

The study was approved by the local Institutional Review Board of the Sleep Disorders Unit (Loewenstein Hospital Rehabilitation Center).

\section{Objective and subjective measurements}

Complete PSG recordings were performed overnight. The recordings were performed using either Nihon Kohden polygraphs (models 4321 and 4414; Nihon Kohden, Tokyo, Japan) or the Rembrandt Manager System (Medcare, Amsterdam, the Netherlands) and included conventional parameters [21]. The recordings were scored according to the standard criteria of ReCHTSCHAFFEN and KALES [22]. Apnoea was defined as an episode of complete breathing cessation of $\geqslant 10 \mathrm{~s}$. Hypopnoea was defined as a reduction of $>30 \%$ in oral/nasal airflow (oral/nasal thermistor) lasting $\geqslant 10 \mathrm{~s}$, accompanied by arousal or by a decrease of $\geqslant 3 \%$ in arterial oxygen saturation $\left(\mathrm{Sa}_{\mathrm{a}} \mathrm{O}_{2}\right)$. Pressure cannulas were not used during the study period. Snoring sounds were recorded by a microphone located above the patient's head at a distance of $1 \mathrm{~m}$ and connected to a sound level meter (SLM; model 2700; Quest Electronics, Oconomowoc, WI, USA). The study procedure used the $\mathrm{dB}$ A scale (A: weighting network that yields the response of the human ear), the $40-100 \mathrm{~dB}$ range and the fast response mode. This was a calibrated channel (40-80 dB) of the PSG in order to evaluate the intensity of each snore event. The output from the SLM was also recorded in parallel on a calibrated (40-80 dB) chart recorder at a paper speed of 
TABLE 2 Demographic and sleep parameters data at baseline (T1) and at the end of the follow-up period (T2)

\begin{tabular}{|c|c|c|c|c|}
\hline Parameter & Subjects $n$ & Mean \pm SD & Median (range) & p-value ${ }^{*}$ \\
\hline \multicolumn{5}{|l|}{ Age yrs } \\
\hline T2 & 160 & $55.8 \pm 11.4$ & $56.9(26-84)$ & \\
\hline \multicolumn{5}{|c|}{ AHI events $\cdot h^{-1}$} \\
\hline $\mathrm{T} 1$ & 160 & $23.0 \pm 22.6$ & $15.1(0.0-99.2)$ & $<0.001$ \\
\hline $\mathrm{T} 1$ & 160 & $29.3 \pm 4.7$ & $28.4(22.0-62.3)$ & $<0.001$ \\
\hline T2 & 160 & $30.1 \pm 4.9$ & $29.4(21.1-51.9)$ & \\
\hline \multicolumn{5}{|l|}{ ESS units } \\
\hline $\mathrm{T} 1$ & 96 & $8.4 \pm 5.1$ & $7.0(0-22)$ & 0.004 \\
\hline T2 & 98 & $10.2 \pm 5.4$ & $10.0(0-23)$ & \\
\hline \multicolumn{5}{|l|}{ Non-REM } \\
\hline $\mathrm{T} 1$ & 156 & $86.1 \pm 8.4$ & $88.0(45.0-97.0)$ & 0.002 \\
\hline T2 & 157 & $84.0 \pm 9.5$ & $84.0(42.0-97.0)$ & \\
\hline \multicolumn{5}{|c|}{ Maximum snoring intensity level $d B$} \\
\hline \multicolumn{5}{|l|}{ Supine } \\
\hline $\mathrm{T} 1$ & 152 & $66.9 \pm 9.0$ & $68.0(40.0-91.0)$ & 0.587 \\
\hline T2 & 144 & $66.9 \pm 9.1$ & $67.0(40.0-96.0)$ & \\
\hline \multicolumn{5}{|l|}{ Lateral } \\
\hline $\mathrm{T} 1$ & 152 & $59.5 \pm 10.1$ & $60.0(40.0-82.0)$ & 0.044 \\
\hline T2 & 157 & $61.0 \pm 10.0$ & $61.0(40.0-92.0)$ & \\
\hline
\end{tabular}

AHI: apnoea/hypopnoea index; BMI: body mass index; ESS: Epworth Sleepiness Scale (0-24); Sa, $\mathrm{O}_{2}$ : arterial oxygen saturation; REM: rapid eye movement. ${ }^{\#}$ : according to Wilcoxon signed rank test analysis. The significance of age is obvious.

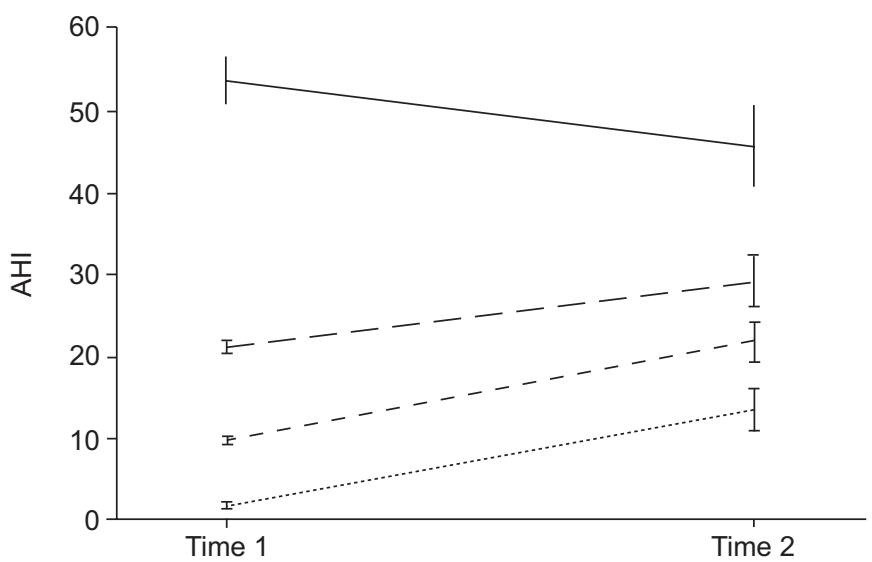

FIGURE 1. The changes in apnoea/hypopnoea index (AHI) over time in 160 untreated patients (mean interval between time 1 and time 2 was $5.1 \pm 3 \mathrm{yrs}$ ) divided into four groups according to diagnosis at time 1. Primary snoring (.......; AHI <5), mild obstructive sleep apnoea (- - - -; AHI 5-15) and moderate obstructive sleep apnoea (---; AHI 15-30) patients had a similar significant increase in $\mathrm{AHI}$, while severe obstructive sleep apnoea patients (—; AHI >30) showed an insignificant decrease in $\mathrm{AHI}$. Data are presented as mean $\pm \mathrm{SE}$.
$10 \mathrm{~cm} \cdot \mathrm{h}^{-1}$. Subjective daytime sleepiness was assessed by using the Epworth Sleepiness Scale (ESS) [23].

\section{Study definitions}

The patients were stratified by apnoea/hypopnoea index $(\mathrm{AHI})$ severity to primary snoring $(\mathrm{AHI}<5)$ and mild (AHI 5-15), moderate (AHI 15-30) and severe OSA (AHI >30). The snoring history was divided into four periods: $<5$ yrs, $5-$ 10 yrs, $10-20$ yrs and $>20$ yrs. An ESS score of $>10$ was considered as abnormal daytime sleepiness. Improvement or worsening of initial AHI was defined as an increase or decrease of $\geqslant 25 \%$ of AHI [5] after assuring that there were $\geqslant 10$ events $\cdot h^{-1}$. A patient was defined as a nonsmoker if there was no history of cigarette smoking or smoking was stopped for $\geqslant 5$ yrs.

\section{Statistical analysis}

As the Shapiro-Wilk test demonstrated that some of the parameters were not normally distributed, the nonparametric Wilcoxon signed rank test was used to compare the mean baseline (time $1 ; \mathrm{T} 1) \mathrm{AHI}$, body mass index $\left(\mathrm{BMI} ; \mathrm{kg} \cdot \mathrm{m}^{-2}\right), \mathrm{ESS}$ score (0-24), lowest $\mathrm{Sa}_{2} \mathrm{O}_{2}$ during rapid eye movement (REM) and non-REM sleep, and maximum snoring sound levels (dB) in supine and lateral body positions with that of end of followup (time 2; T2). The nonparametric Kruskall-Wallis test was 
TABLE 3 Change in sleep parameters over time for the four patient groups at baseline (T1) and at the end of the follow-up period (T2)

AHI severity groups

Differences among

groups

\begin{tabular}{llll}
\hline Primary snoring $^{\#} \quad$ Mild OSA & Moderate OSA & Severe OSA $^{\text {§ }}$
\end{tabular}

\section{Subjects $n$}

Age yrs

$\mathrm{T} 1$

T2

$\Delta$ age

$\mathrm{p}$-value

AHI events $\cdot h^{-1}$

$\mathrm{T} 1$

T2

$\triangle \mathrm{AHI}$

p-value

BMI $\mathbf{k g} \cdot \mathrm{m}^{-2}$

$\mathrm{T} 1$

T2

$\Delta \mathrm{BMI}$

p-value

Lowest $\mathrm{Sa}, \mathrm{O}_{2} / \mathrm{REM}$

T1

T2

$\Delta$ lowest $\mathrm{Sa}, \mathrm{O}_{2} / \mathrm{REM}$

p-value

Lowest $\mathrm{Sa}, \mathrm{O}_{2} /$ non-REM

$\mathrm{T} 1$

T2

$\Delta$ lowest $\mathrm{Sa}_{1} \mathrm{O}_{2} /$ non-REM

$\mathrm{p}$-value

ESS

T1

T2

$\Delta \mathrm{ESS}$

$\mathrm{p}$-value
$48.8 \pm 10.5$

$55.0 \pm 10.2$

$6.2 \pm 2.6$

$1.8 \pm 1.6$

$13.4 \pm 12.9$

$11.7 \pm 12.8$

$<0.001$

$26.6 \pm 3.3$

$27.8 \pm 3.6$

$1.2 \pm 2.1$

0.005

$91.3 \pm 3.4$

$90 \pm 4.1$

$-1.4 \pm 5.2$

0.205

$92 \pm 3$

$89.8 \pm 3.7$

$-2.2 \pm 3.4$

0.006

$7.8 \pm 5.3$

$7.9 \pm 4.8$

$0.8 \pm 5.6$

0.594
49

$$
\begin{gathered}
51.7 \pm 12.0 \\
57.1 \pm 12.2 \\
5.4 \pm 3.0
\end{gathered}
$$

$9.1 \pm 3.3$

$21.7 \pm 16.7$

$12.6 \pm 16.4$

$<0.001$

$28.7 \pm 3.3$

$30.2 \pm 4.2$

$1.4 \pm 2$

$<0.001$

87. \pm 8.6

$83.4 \pm 12.3$

$-3.5 \pm 11.2$

0.046

89.3. \pm 4

$86.3 \pm 5$

$-3.1 \pm 5.5$

$<0.001$
$8.9 \pm 4.8$
$10.2 \pm 5.4$
$2.2 \pm 5.2$
0.090

41

$49.6 \pm 10.5$
$54.5 \pm 10.8$

$4.9 \pm 3.0$

$21 \pm 4.2$

$29 \pm 19.3$

$8.1 \pm 19.6$

0.025

$28.8 \pm 3.4$

$29.5 \pm 4.5$

$0.7 \pm 2.3$

0.187

$83 \pm 8$

$78.1 \pm 15.2$

$-4.9 \pm 14.3$

0.093

$85.2 \pm 5.6$

$82.3 \pm 11.2$

$-3 \pm 11.4$

0.462

$8.7 \pm 5.1$

$11.0 \pm 5.2$

$2.9 \pm 4.9$

0.050

42

$\begin{array}{cc}51.6 \pm 12.2 & 0.657 \\ 55.9 \pm 12.2 & 0.731 \\ 4.3 \pm 3.1 & 0.044\end{array}$

$52.6 \pm 2$

$\leqslant 0.001$

$45.6 \pm 30.2$

$\leqslant 0.001$

$\leqslant 0.001$

0.051

$31.4 \pm 4.3$

$\leqslant 0.001$

$31.5 \pm 5.3$

$0.1 \pm 3.3$

0.995

0.003

0.011

$75 \pm 14.3$

$\leqslant 0.001$

$73.7 \pm 17.9$

$\leqslant 0.001$

$-1.3 \pm 14.2$

0.871

0.339

$79.4 \pm 11.8$

$\leqslant 0.001$

$80 \pm 11.7$

$0.6 \pm 11.3$

$\leqslant 0.001$

0.057

0.728

$\begin{array}{cc}8.1 \pm 5.5 & 0.919 \\ 11.3 \pm 5.6 & 0.174 \\ 2.1 \pm 5.2 & 0.775\end{array}$

AHI: apnoea/hypopnoea index; OSA: obstructive sleep apnoea; BMI: body mass index; $\mathrm{Sa}, \mathrm{O}_{2}$ : arterial oxygen saturation; REM: rapid eye movement; ESS: Epworth Sleepiness Scale. ${ }^{\#}$ : AHI $<5$; ${ }^{\circ}$ : AHI $5-15{ }^{+}{ }^{+}$: AHI $15-30$; ${ }^{\text {s: }}$ AHI $\geqslant 30$. The p-values between groups are according to the Kruskall-Willis test and the p-values for differences between $\mathrm{T} 1$ and $\mathrm{T} 2$ are according to Wilcoxon signed rank test.

used to examine differences over time of the four AHI severity groups for a given demographic or sleep parameter $(\Delta$ indicates difference between T1 and T2). Stepwise linear regression was used to examine the correlations between $\triangle \mathrm{AHI}$ as the dependent variable against $\triangle \mathrm{BMI}$, time between recordings (TBR), age, $\mathrm{HT}$ and/or $\mathrm{CVD}$, and lowest $\mathrm{Sa}_{\mathrm{a}} \mathrm{O}_{2}$ levels during REM and non-REM sleep. Stepwise logistic regression analysis determined the independent risk factors for HT and/ or CVD. Only variables that were significant were entered into the final multiple logistic regression model.

\section{RESULTS}

In total, 160 untreated adult males (mean age $51 \pm 11$ yrs) underwent full PSG recordings on two occasions (mean TBR $5.1 \pm 3$ yrs; median (range) 5 (0.5-15) yrs). The mean sleep efficiency was $85.6 \pm 8.9 \%$ for the first PSG and $85.5 \pm 8.1 \%$ for the follow-up evaluation.
Table 2 shows the values of age, AHI, BMI, ESS, lowest $\mathrm{Sa}_{1} \mathrm{O}_{2}$ in REM and non-REM sleep, and maximum snoring sound levels $(\mathrm{dB})$ in supine and lateral body positions for T1 and T2. The significant increase in age is obvious. The Wilcoxon signed rank test shows a significant increase for AHI and BMI levels, and a significant decrease (worsening) in lowest $\mathrm{Sa}_{1} \mathrm{O}_{2}$ in REM and non-REM sleep. There was also a significant increase in ESS score from $\mathrm{T} 1$ to $\mathrm{T} 2$. The snoring intensity in the supine body position did not change significantly; however, in the lateral position a significant increase was observed.

Primary snoring was diagnosed in $26(16.3 \%)$ patients, mild OSA in $47(29.4 \%)$, moderate OSA in $41(25.6 \%)$, and severe OSA in $40(25 \%)$ patients. The TBR was significantly different across these patient groups $(6.2 \pm 2.6,5.4 \pm 3.0,4.9 \pm 3.0$ and $4.3 \pm 3.1 \mathrm{yrs}$, respectively; $\mathrm{p}=0.044)$. The $\Delta \mathrm{AHI}$ differed significantly among the groups, showing two patterns (a significant 

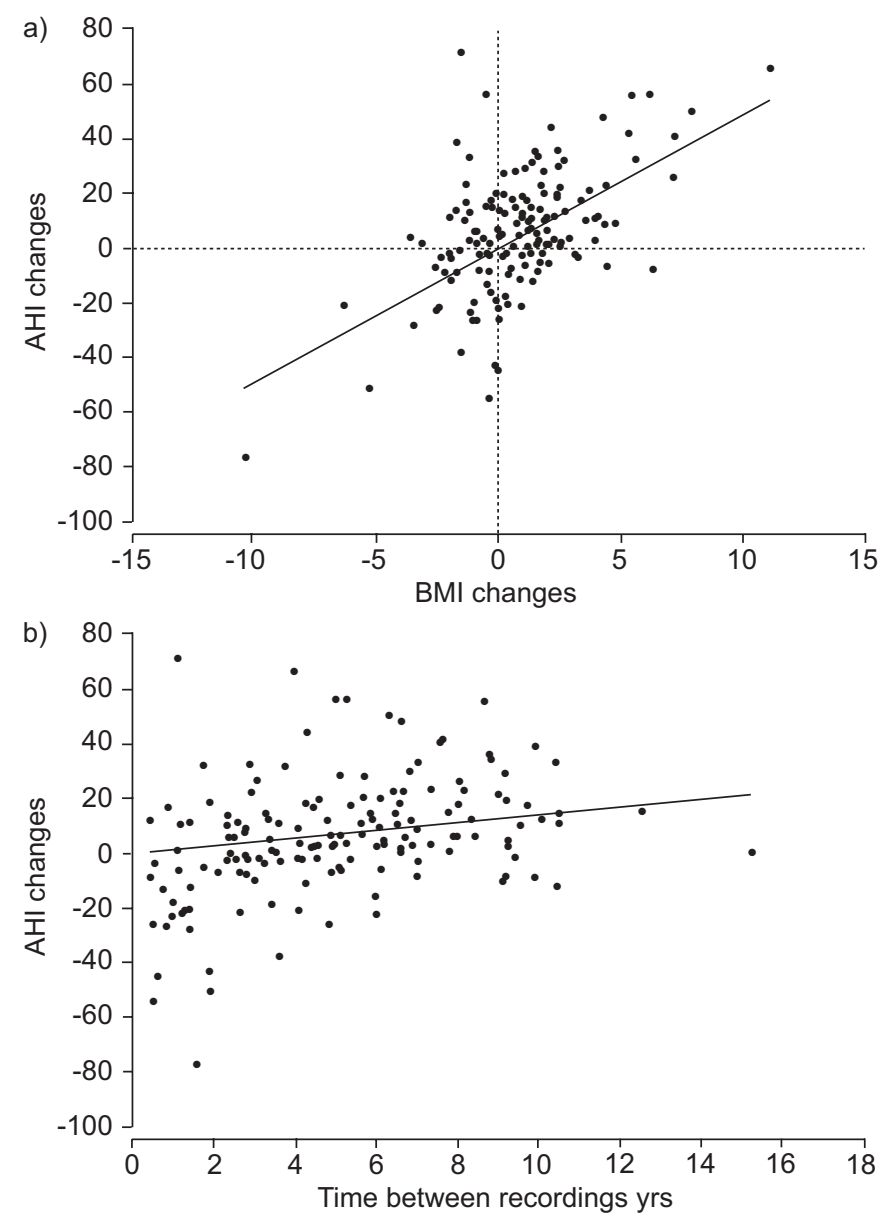

FIGURE 2. a) The relationship between the change in apnoea/hypopnoea index (AHI) and the change in body mass index (BMI) for the 160 untreated patients who had two complete polysomnographic evaluations during a mean period of $\sim 5 \mathrm{yrs}$. $y=4.9307 x ; r^{2}=0.258 ; p<0.001$. b) The relationship between the change in $\mathrm{AHI}$ and time between recordings for the 160 untreated patients who had two complete polysomnographic evaluations during a mean period of $\sim 5 \mathrm{yrs}$. $y=1.4368 x ; r^{2}=0.0815 ; p<0.001$.

increase for primary snoring, mild OSA and moderate OSA and an insignificant decrease for severe OSA; fig. 1). The difference for $\triangle \mathrm{BMI}$ was also significant among the groups $(p=0.011)$. While primary snoring and mild OSA patients had a significant worsening in BMI, moderate and severe OSA patients did not show significant increases in BMI (table 3). The lowest $\mathrm{Sa}_{1} \mathrm{O}_{2}$ level in REM and non-REM sleep showed significant differences among the groups but no significant interaction with time was observed. A significant deterioration was observed for the lowest $\mathrm{Sa}_{1} \mathrm{O}_{2}$ level in REM sleep for patients with mild OSA and for the lowest $\mathrm{Sa}_{\mathrm{a}} \mathrm{O}_{2}$ level in nonREM sleep for primary snorers and mild OSA patients. As for $\triangle \mathrm{AHI}$, patients with severe OSA showed an insignificant change in $\mathrm{Sa}_{1} \mathrm{O}_{2}$ for both REM sleep and non-REM sleep (table 3). Although moderate OSA patients showed a significant increase in ESS score, the change in ESS score was not statistically significant across groups or across time. The significant correlations between $\triangle \mathrm{AHI}$ and $\triangle \mathrm{BMI}\left(\mathrm{r}^{2}\right.$ linear $=0.296)$ and $\Delta$ AHI and TBR $\left(r^{2}\right.$ linear $\left.=0.082\right)$ are displayed in figure 2.

\begin{tabular}{|c|c|c|c|c|}
\hline \multirow[t]{3}{*}{ TABLE 4} & \multicolumn{4}{|c|}{$\begin{array}{l}\text { Age, body mass index (BMI) and apnoea/ } \\
\text { hypopnoea index (AHI) of patients who } \\
\text { improved, did not change, or worsened between } \\
\text { baseline (T1) and follow-up (T2) }\end{array}$} \\
\hline & \multicolumn{3}{|c|}{ AHI groups } & \multirow[t]{2}{*}{$p$-value } \\
\hline & Improved & Unchanged & Worsened & \\
\hline Subjects & $23(14.4)$ & $74(46.2)$ & $63(39.4)$ & \\
\hline \multicolumn{5}{|l|}{ Age yrs } \\
\hline $\mathrm{T} 1$ & $52.8 \pm 13.7$ & $50.9 \pm 10.5$ & $49.5 \pm 11.5$ & 0.478 \\
\hline T2 & $55.7 \pm 13.5$ & $56 \pm 10.8$ & $55.6 \pm 11.6$ & 0.978 \\
\hline \multicolumn{5}{|l|}{ BMI $\mathrm{kg} \cdot \mathrm{m}^{-2}$} \\
\hline $\mathrm{T} 1$ & $29.8 \pm 4.1$ & $29.4 \pm 5.8$ & $29 \pm 3.4$ & 0.782 \\
\hline T2 & $28.3 \pm 3.5$ & $30 \pm 5.4$ & $30.8 \pm 4.8$ & 0.107 \\
\hline \multicolumn{5}{|c|}{ AHI events $\cdot h^{-1}$} \\
\hline $\mathrm{T} 1$ & $40.9 \pm 19$ & $22.4 \pm 26.4$ & $16.2 \pm 14.4$ & $<0.001$ \\
\hline T2 & $13.2 \pm 8.9$ & $23.2 \pm 24.7$ & $41.4 \pm 21.6$ & $<0.001$ \\
\hline
\end{tabular}

Stepwise linear regression analysis showed that $\triangle \mathrm{BMI}$ and TBR were significant predictors for AHI change $(95 \%$ confidence interval (CI) 2.72-4.92, $\mathrm{p}<0.001$; 95\% CI 0.6-2.66, $\mathrm{p}=0.002$, respectively; $\mathrm{r}^{2}=0.331$ ), whereas baseline age, $\mathrm{BMI}, \mathrm{HT}$ and/or CVD, and lowest $\mathrm{Sa}_{2} \mathrm{O}_{2}$ in REM and non-REM sleep were not. Adjusting for these confounding factors, a model for the mean $\Delta \mathrm{AHI}$ showed that: $\Delta \mathrm{AHI}=(4.33 \times \Delta \mathrm{BMI})+(0.66 \times \mathrm{TBR})$; $\mathrm{r}^{2}=0.322$.

A cut-off point of $25 \%$ [8] was used to define improvement or worsening of initial AHI (table 4). In total, 23 (14.4\%) patients improved their initial AHI score, 74 (46.2\%) remained stable and $63(39.4 \%)$ patients worsened. No significant differences were found between these three groups in terms of age and BMI. Patients who showed a worsening effect had a significantly lower $\mathrm{AHI}$ at $\mathrm{T} 1$ and patients who improved had a significantly higher AHI at T1.

Table 5 shows that the incidence of HT and/or CVD increased from $54(33.8 \%)$ patients at T1 to $65(40.6 \%)$ patients at T2.

\begin{tabular}{|c|c|c|c|c|c|c|}
\hline \multicolumn{2}{|c|}{ TABLE 5} & \multicolumn{5}{|c|}{$\begin{array}{l}\text { Number of patients with hypertension (HT) and } \\
\text { cardiovascular disease (CVD) at baseline (T1) } \\
\text { and end of follow-up (T2) }\end{array}$} \\
\hline & \multirow{2}{*}{$\begin{array}{c}\text { HT } \\
\text { alone }\end{array}$} & \multirow{2}{*}{$\begin{array}{l}\text { CVD } \\
\text { alone }\end{array}$} & \multirow{2}{*}{$\begin{array}{l}\text { HT and } \\
\text { CVD }\end{array}$} & \multicolumn{3}{|c|}{ Total } \\
\hline & & & & HT & CVD & $\begin{array}{c}\text { HT and/or } \\
\text { CVD }\end{array}$ \\
\hline T1 & $32(20)$ & $11(6.9)$ & $11(6.9)$ & $43(26.9)$ & $22(13.8)$ & $54(33.8)$ \\
\hline T2 & $41(25.6)$ & $9(5.6)$ & $15(9.4)$ & $56(35)$ & $24(15)$ & 65 (40.6) \\
\hline T2-T1 & $9(5.6)$ & $-2(-1.3)$ & $4(2.5)$ & $13(8.1)$ & $2(1.3)$ & $11(10.4)$ \\
\hline
\end{tabular}




\begin{tabular}{|c|c|c|c|}
\hline \multirow[t]{2}{*}{ TABLE 6} & \multicolumn{3}{|c|}{$\begin{array}{l}\text { Risk factors for developing hypertension (HT) } \\
\text { and/or cardiovascular disease (CVD) }\end{array}$} \\
\hline & $\begin{array}{l}\text { HT and/or } \\
\text { CVD }\end{array}$ & $\begin{array}{l}\text { No HT } \\
\text { and/or CVD }\end{array}$ & OR (95\% Cl) \\
\hline Subjects $\mathrm{n}$ & 65 & 90 & \\
\hline Age/T2 yrs & $60.4 \pm 11.6$ & $52.8 \pm 10.2$ & $1.08(1.04-1.12)$ \\
\hline $\mathrm{BMI} / \mathrm{T} 2$ units & $31 \pm 4.7$ & $29.2 \pm 4.6$ & $1.13(1.04-1.22)$ \\
\hline \multicolumn{4}{|c|}{$\begin{array}{l}\text { The number of patients exceeds } 160 \text { because patients may have more than one } \\
\text { disease. OR: odds ratio; Cl: confidence interval; T2: end of the follow-up } \\
\text { period; BMI: body mass index. }\end{array}$} \\
\hline
\end{tabular}

Table 5 also shows that $11(10.4 \%)$ out of 106 patients who had no HT at T1 developed this complication during T2. In nine $(81.8 \%)$ patients, there was an increase in BMI and AHI at T2 (data not shown).

Analysis by age, BMI, AHI at T2, duration of snoring, and smoking habits as independent risk factors for HT and/or CVD showed that age, BMI and AHI were positively associated with HT and/or CVD $(60.4 \pm 11.6$ versus $52.8 \pm 10.2, \mathrm{p}=0.017 ; 31.0 \pm 4.7$ versus $29.2 \pm 4.6, \mathrm{p}=0.026$; and $31.8 \pm 22.7$ versus $25.7 \pm 23.8, \mathrm{p}=0.038$; respectively), whereas duration of snoring $(p=0.094)$ and smoking habits $(p=0.395)$ were not. Using the significant variables identified and adjusting for confounding factors, multiple regression analysis indicated that only age and higher levels of BMI remained significant risk factors for developing HT and/or CVD (table 6).

\section{DISCUSSION}

The main finding of the present study is that the outcome of untreated primary snorers and OSA patients in the adult male study population is dependent mainly on weight increase and, to a lesser degree, on time. Of these two factors, weight increase exceeds the latter by almost seven-fold, having a major role in AHI progression. Age, HT and lowest $\mathrm{Sa}_{1} \mathrm{O}_{2}$ in REM and non-REM sleep were not significant predictors for AHI progression.

Provided that $\triangle \mathrm{BMI}$ and TBR are known, the current authors' model for calculating $\Delta \mathrm{AHI},(4.33 \times \Delta \mathrm{BMI})+(0.66 \times \mathrm{TBR})$, may serve as a useful tool in sleep healthcare medicine for male patients aged $\sim 50 \mathrm{yrs}$, who are the vast majority of male patients seeking treatment for snoring and OSA at the sleep disorder units. It may be deduced from the model that with a stable body weight, it takes $\geqslant 6$ yrs before the impact of TBR on $\triangle \mathrm{AHI}$ perhaps becomes apparent (increased in four units in $\triangle \mathrm{AHI}$ ). However, increasing weight in one BMI unit during $1 \mathrm{yr}$, the AHI will increase in five units. Previous studies have also shown the role of time in disease progression in the absence of concomitant weight increase [5, 24], and for some cases it is possible that AHI could be a risk factor for an increase in the BMI.

The number of patients included in the present study exceeds that of all previous studies available to date on the natural evolution of primary snoring and OSA for patients seeking treatment (table 1), allowing the present authors to establish a more meaningful statistical analysis for the four subsets of disease severity.

A significant increase in $\mathrm{AHI}$ and $\mathrm{BMI}$ over time was shown in the 160 males with primary snoring and various degrees of OSA. Nevertheless, while snorers and those with mild and moderate OSA had an increase in AHI that correlated with the increase in BMI, patients with severe OSA had a nonsignificant decrease in AHI suggesting a ceiling effect for OSA severity.

The correlation between $\triangle \mathrm{AHI}$ and $\triangle \mathrm{BMI}$ is demonstrated in several studies of patients seeking treatment. In patients aged $>70$ yrs, ANCOLI-ISRAEL et al. [18] showed that changes in AHI were associated with changes in BMI and, similarly to the present findings, this was independent of age. Furthermore, SFORZA et al. [15] did not observe significant changes in apnoea frequency or nocturnal hypoxaemia in untreated OSA patients in the absence of changes in BMI. Likewise, no AHI changes were detected in untreated OSA patients who remained stable in weight, but those who reduced their weight had a significant decrease in AHI severity [15].

Similar to previous studies [5-7], using a cut-off point of $25 \%$ for defining improvement or worsening of initial AHI [5], the current authors showed no significant differences in the age of patients who improved, remained stable or deteriorated $(p=0.478)$. Another study found a tendency for younger patients to deteriorate [15].

The association between sleep-disordered breathing and HT is well established [25]. In total, 42 (26.9\%) of the study patients were initially diagnosed with HT. During the follow-up period, $10.4 \%$ of normotensive patients developed this complication, demonstrating a more than two-fold increase in the incidence of HT than the expected incidence of newly diagnosed HT in the general population over a similar period [26]. Similar to a previous study [27], the current authors found that age and high levels of BMI were significant predictors of HT and/or CVD while the progression in AHI itself was not the main factor in the development of CVD. Certainly, other cardiovascular risk factors not assessed in the present study, such as dyslipidaemia, insulin resistance or endothelial dysfunction, may have also participated in the development of cardiovascular morbidity.

The present study has several limitations. A retrospective design is of one the known limitations of studies covering the natural history of snoring and OSA. However, it allowed a better insight into the long-term trends of this syndrome in a relatively large group of untreated patients who had at least two PSG evaluations. A second limitation is that the patients consisted of a seek-treatment group and, regardless of the mode of referral, they were assessed mainly because their sleep symptoms and/or daytime somnolence either continued or worsened. This may have induced a selection bias, as patients with severe or progressive symptoms are more eager to be reexamined. Nevertheless, it may have been balanced by the fact that most of the severe OSA patients are being successfully treated with CPAP, underwent surgery or use other devices and were all excluded from the analysis. Moreover, in the current study population, there were a similar number of patients with mild, moderate and severe OSA that had two PSG evaluations. 
Using a cut-off point of $25 \%$ for defining improvement or worsening of initial AHI, although used in a previous study [5], is arbitrary and could be affected by the night-to-night AHI variability. In addition, since mild-to-moderate OSA patients are mainly influenced by the sleep posture, it is possible that part of the increase in AHI severity is related to an increase in time spent in the supine posture in the second PSG [21]. However, since only a significant increase in lateral AHI $(19.4 \pm 19.6$ versus $28.9 \pm 25.7 ; \mathrm{p}<0.01)$ was seen, without a significant change in supine AHI $(58.8 \pm 32.4$ versus $59.4 \pm 27.4)$ from $\mathrm{T} 1$ to $\mathrm{T} 2$, this does not appear to be the case.

Unfortunately, the current authors did not quantify the various reasons for seeking a repeated PSG evaluation in the study patients, which could have provided valuable clinical information. However, based on clinical experience, the main two reasons for a re-evaluation were a suspected worsening of snoring and/or OSA and a subjective worsening in daytime sleepiness. In some cases, the trigger for a re-evaluation came after reading a related article in a newspaper or magazine, after watching or listening to a television or radio programme, or after the recommendations of a friend using CPAP successfully.

How do these data compare to data obtained from the general population? The crucial role of weight gain on the progression of snoring and OSA shown in the present study in seekingtreatment patients is very similar to most of the previous studies that have investigated the evolution of snoring and OSA in the general population. Population studies of the Wisconsin Sleep Cohort [7], the Cleveland Family Study [9] or from the Sleep Heart Health Study [10] all found that weight gain is a crucial predictor of longitudinal changes in the incidence and severity of sleep-disordered breathing. Although this association between increase in weight and the worsening in sleep-disordered breathing has modifications according to sex, age, race and ethnicity, it is clear that excess weight is a critical contributor to the incidence and progression of this sleep related breathing disorder. Thus, the results of the largest untreated clinical population of seeking-treatment patients suffering from snoring and OSA agree completely with the results of the largest population study [10], and support the notion that avoiding weight gain for the prevention of and encouraging weight loss for the treatment of this clinical entity are imperative purposes for public health.

In summary, in a follow-up study of 160 untreated snorers and obstructive sleep apnoea adult male patients over a mean period of $5 \mathrm{yrs}$, it was found that patients with primary snoring and mild and moderate obstructive sleep apnoea had a similar significant increase in apnoea/hypopnoea index over time. However, patients with severe obstructive sleep apnoea had an insignificant change in apnoea/hypopnoea index suggesting a ceiling effect. The progression in apnoea/hypopnoea index is mainly dependent on weight gain and, to a lesser degree, on time. Of these two factors, weight increase exceeds the latter by almost seven-fold, having a major role in apnoea/hypopnoea index progression. Provided that change in body mass index and time between recordings are known, the current authors model for calculating change in apnoea/hypopnoea index may represent a useful tool in sleep healthcare medicine for male patients aged $\sim 50$ yrs, who are the vast majority of male patients seeking treatment for snoring and obstructive sleep apnoea.

\section{REFERENCES}

1 Lugaresi E, Cirignotta F, Gerardi R, et al. Snoring and sleep apnoea: natural history of heavy snorers disease. In: Guilleminault C, Partinen M, eds. Obstructive Sleep Apnoea Syndrome. Clinical Research and Treatment. New York, Raven Press, 1989; pp. 25-36.

2 Bliwise D, Carskadon M, Carey E, Dement W. Longitudinal development of sleep-related respiratory disturbance in adult humans. J Gerontol 1984; 39: 290-293.

3 Phoha RL, Dickel MJ, Mosko SS. Preliminary longitudinal assessment of sleep in the elderly. Sleep 1990; 13: 425-429.

4 Svanborg E, Larsson H. Development of nocturnal respiratory disturbance in untreated patients with obstructive sleep apnoea syndrome. Chest 1993; 104: 340-343.

5 Pendlebury ST, Pepin JL, Veale D, Lévy P. Natural evolution of moderate sleep apnoea syndrome: significant progression over a mean of 17 months. Thorax 1997; 52: 872-878.

6 Lindberg E, Elmasry A, Gislason T, et al. Evolution of sleep apnoea syndrome in sleepy snorers. A population-based prospective study. Am J Respir Crit Care Med 1999; 159: 2024-2027.

7 Peppard PE, Young T, Palta M, Dempsey J, Skatrud J. Longitudinal study of moderate weight changes and sleepdisordered breathing. JAMA 2000; 284: 3015-3021.

8 Young T, Peppard PE, Gotlieb DJ. Epidemiology of obstructive sleep apnoea. Am J Respir Crit Care Med 2002; 165: 1217-1239.

9 Redline S, Schluchter MD, Larkin EK, Tishler PV. Predictors of longitudinal change in sleep-disordered breathing in a nonclinic population. Sleep 2003; 26: 703-709.

10 Newman AB, Foster G, Givelber R, Nieto FJ, Redline S, Young T. Progression and regression of sleep-disordered breathing with changes in weight: the Sleep Heart Health Study. Arch Intern Med 2005; 165: 2408-2413.

11 Sahlman J, Pukkila M, Seppä J, Tuomilehto H. Evolution of mild obstructive sleep apnoea after different treatments. Laryngoscope 2007; 117: 1107-1111.

12 Mason WJ, Ancoli Israel S, Kripke DF. Apnoea revised: a longitudinal follow up. Sleep 1989; 12: 423-429.

13 Rosenthal LD, Roehrs TA, Roth T. Natural course of sleep apnoea: a two year follow up. In: Kuna ST, Surrat PM, Remmers JE eds. Sleep and Respiration in Aging Adults. New York, Elsevier, 1991; p. 348.

14 Ancoli-Israel S, Kripke DF, Klauber MR, et al. Natural history of sleep disordered breathing in community dwelling elderly. Sleep 1993; 16: Suppl. 8, S25-S29.

15 Sforza E, Addati G, Cirignotta F, Lugaresi E. Natural evolution of sleep apnoea syndrome: a five year longitudinal study. Eur Respir J 1994; 7: 1765-1770.

16 Hoch CC, Dew MA, Reynolds CF 3rd, et al. Longitudinal changes in diary- and laboratory-based sleep measures in healthy "old old" and "young old" subjects: a three-year follow-up. Sleep 1997; 20: 192-202.

17 Quan SF. Evolution of OSA. Thorax 1998; 53: 532.

18 Ancoli-Israel S, Gehrman P, Kripke DF, et al. Long-term follow-up of sleep disordered breathing in older adults. Sleep Med 2001; 2: 511-516.

19 Fisher D, Pillar G, Malhotra A, Peled N, Lavie P. Longterm follow-up of untreated patients with sleep apnoea syndrome. Respir Med 2002; 96: 337-343. 
20 Lavie P. Sleep medicine - time for a change. J Clin Sleep Med 2006; 2: 207-211.

21 Oksenberg A, Silverberg DS, Arons E, Radwan H. Positional vs nonpositional obstructive sleep apnoea patients. Anthropomorphic, nocturnal polysomnographic and multiple sleep latency test data. Chest 1997; 112: 629-639.

22 Rechtschaffen A, Kales A, eds. A manual of standardized terminology techniques and scoring system for sleep stages of human subjects. Bethesda, National Institute for Neurological Diseases and Blindness, Neurological Information Network, 1968.

23 Johns MW. A new method for measuring daytime sleepiness: the Epworth Sleepiness Scale. Sleep 1991; 14: 540-545.
24 Pillar G, Peled R, Lavie P. Recurrence of sleep apnoea without concomitant weight increase 7.5 years after weight reduction surgery. Chest 1994; 106: 1702-1704.

25 Peppard PE, Young T, Palta M, Skatrud J. Prospective study of the association between sleep disordered breathing and hypertension. N Engl J Med 2000; 342: 1378-1384.

26 Bakx JC, van den Hoogen HJ, van den Bosch WJ, et al. Development of blood pressure and the incidence of hypertension in men and women over an 18-year period: results of the Nijmegen Cohort Study. J Clin Epidemiol 1999; 52: 531-538.

27 Lavie P, Lavie L, Herer P. All-cause mortality in males with sleep apnoea syndrome: declining mortality rates with age. Eur Respir J 2005; 25: 514-520. 